\title{
Improved rhizosphere competence in a protoplast fusion progeny of Trichoderma harzianum
}

\author{
A. Sivan $\dagger$ and G. E. HaRman* \\ Department of Horticultural Sciences, Cornell University, New York State Agricultural Experiment Station, Geneva, \\ NY 14456, USA
}

(Received 5 June 1990; revised 6 September 1990; accepted 11 September 1990)

\begin{abstract}
The level and pattern of rhizosphere competence of a strain of Trichoderma harzianum (1295-22) derived from fusing protoplasts of auxotrophic mutants of the prototrophic strains T12 and T95 were studied and compared with those of the original strains. Colonization of the rhizosphere by the three strains was tested after treating seeds of cotton and maize with conidia and planting them in soil at a constant moisture content. Propagules of the fungi were removed by a washing technique, Trichoderma spp. were isolated by plating serial dilutions on a selective medium, and individual strains were identified by their characteristic growth on differential media. Both strains T12 and T95 colonized the entire length of maize roots, but strain 1295-22 was more effective in colonizing the middle sections of the roots than either parental strain. All strains colonized cotton roots more poorly than maize roots; strains T12 and T95 were not detected on some root segments of this crop. Strain T95 was, however, found on the root tip, while T12 was absent from this root portion. Conversely, strain 1295-22 colonized all root sections of this crop, and its population levels were higher in the middle root portions than those of either parental strain.
\end{abstract}

\section{Introduction}

Rhizosphere competence enables micro-organisms to proliferate and establish along the developing rhizosphere following seed treatments (Ahmad \& Baker, 1987 a; Burr et al., 1978; Chao et al., 1986; Elliott Juhnke et al., 1987; Sivan \& Chet, 1989). Seed treatments with beneficial micro-organisms are an attractive way to apply microbial antagonists. The ability of such microorganisms to colonize the rhizosphere may be crucial for optimal expression of their biological activity (Schmidt, 1979).

Trichoderma spp. have probably been more thoroughly studied than any other fungal antagonists (Papavizas, 1985; Chet, 1987; Harman, 1990). Rhizosphere competence has been identified only recently in this genus (Papavizas, 1982; Chao et al., 1986; Ahmad \& Baker, $1987 a)$ and has been demonstrated only in benomyltolerant mutants (Ahmad \& Baker, 1988) and one wild strain (Sivan \& Chet, 1989).

Rhizosphere competence can be induced in wild

†Present address: The Institutes for Applied Research, Ben Gurion University, PO Box 1025, Beer-Sheva 84110, Israel.

Abbreviations: PDA, potato dextrose agar; TSM, Trichoderma selective medium; CCNS, cycloheximide/chlorotetracycline/nystatin/ streptomycin sulphate medium; a.i., active ingredient. strains by mutagenesis or genetic manipulation. Ahmad \& Baker (1987a) induced rhizosphere competence in Trichoderma harzianum by mutagenesis. Progeny from protoplast fusion (Stasz et al., 1988) exhibited better biocontrol activity and more effectively colonized the rhizosphere of several crops than did the strains from which they were derived (Harman et al., 1989). Abstracts of this work have appeared elsewhere (Sivan \& Harman, 1989, 1990).

The objective of this study was to compare the rhizosphere competence of a strain derived from protoplast fusion relative to those of the parental strains. The level and pattern of colonization of both the rhizosphere soil and rhizoplane were determined for a dicotyledonous and a monocotyledonous crop plant.

\section{Methods}

Fungal strains. Two strains of Trichoderma harzianum Rifai served as parental strains: T95 (ATCC 60850), which is a benomyl-resistant and rhizosphere-competent mutant (Ahmad \& Baker, 1987a) that controls Pythium ultimum (Ahmad \& Baker, 1988); and T12 (ATCC 20737), which has been used as a biological seed and seedling rot protectant against several pathogens (Hadar et al., 1984; Harman et al., 1989). Protoplasts of lysine- and histidine-auxotrophic mutants of T95 and T12, respectively (Stasz et al., 1988), were fused and a strain (1295-22) was selected and found to be a better biocontrol agent than either prototrophic parent strain (Harman et al., 1989). Strain 1295-22 was 
prototrophic, grew more rapidly than the parental strains, and was stable through many cell cycles. The sensitivity to benomyl and the isoenzyme electrophoretic pattern of this strain were identical to those of T12 (Harman et al., 1989). All strains were cultured on a potato dextrose agar medium (PDA; Difco) at $25^{\circ} \mathrm{C}$.

Test crops. Cotton (Gossypium sp. L. cv. 'Deltapine 61') and maize (Zea mays L. cv. 'Jubilee') were utilized to represent dicotyledonous and monocotyledonous crops, respectively.

Seed treatments. Conidial suspensions were obtained from cultures grown on PDA by scraping conidia from the agar surface with a spatula and suspending them in sterile water. The suspensions were filtered through four layers of sterile lens paper to remove hyphal debris. The conidial concentration was adjusted to $1-4 \times 10^{9}$ conidia $\mathrm{ml}^{-1}$. Pelgel (The Nitragin Co. Milwaukee, WI, USA) was added at a concentration of $10 \%(\mathrm{w} / \mathrm{v})$ as an adhesive (Harman et al., 1981).

Seeds were treated by applying $1 \mathrm{ml}$ of the conidial suspension to 7.8 and $10.5 \mathrm{~g}$ seeds of cotton and maize, respectively. This treatment resulted in 1-2 $2 \times 10^{6}$ and $2-3 \times 10^{6}$ colony-forming units (c.f.u.) per seed of cotton and maize, respectively. The viable $T$. harzianum population on treated seeds was determined by shaking $1 \mathrm{~g}$ treated seeds in $25 \mathrm{ml}$ sterile water amended with $100 \mu$ l alkylaryl polyether alcohol (Triton X-100; J. T. Baker Chemical Co.) from which serial dilutions were plated on a Trichoderma selective medium (TSM) (Harman et al., 1989) containing $\left(\mathrm{g}^{-1}\right): \mathrm{Ca}\left(\mathrm{NO}_{3}\right)_{2}, 1 \cdot 0 ; \mathrm{KNO}_{3}, 0 \cdot 25$; $\mathrm{MgSO}_{4}, 0.25 ; \mathrm{KH}_{2} \mathrm{PO}_{4}, 0.125 ; \mathrm{CaCl}_{2} .2 \mathrm{H}_{2} \mathrm{O}, 1.0$; citric acid (diammonium salt), 0.05 ; sucrose, $2 \cdot 0$; Igepal Co-630 (Applied Science, State College, PA, USA), $1.1 \mathrm{ml}$. The $\mathrm{pH}$ was adjusted to 4.5 using $\mathrm{NaOH}$. After autoclaving, the medium was amended with ( $\left.\mathrm{mg} \mathrm{l}^{-1}\right)$ chlorotetracycline, 50 ; captan ( $N$-trichloromethylthio-4-cyclohexene-1,2-dicarboximide), 20 (a.i.) and ronilan [3-(3,5-dichlorophenyl)-5-ethenyl-5methyl-2,4-oxazolidinedione] $2 \cdot 5$ (a.i.). Seeds treated with Pelgel alone served as controls.

Soil. An Arkport fine sandy loam of $\mathrm{pH} 7 \cdot 3$ was used. Its nutritional composition was reported by Hubbard et al. (1983). The moisture content was adjusted to -70 mbar ( $14 \%$ moisture content).

Rhizosphere competence assay. The rhizosphere soil and rhizoplane colonization pattern and level obtained by $T$. harzianum strains, following their application as seed treatments, was tested using methods developed by Scher et al. (1984) as modified by Ahmad \& Baker (1987a) and Sivan \& Chet (1989). Two longitudinal halves of $25 \mathrm{~cm}$ long polyvinylchloride pipes $(2.2 \mathrm{~cm}$ in diameter) were secured with rubber bands to form a column and filled with soil. The soil columns were tapped in order to compact the soil and generate a uniform column ending $1 \mathrm{~cm}$ below the rim of the pipe. One seed was placed at the top of each soil column. Twenty columns of each treatment were vertically placed in a plastic box containing soil at the same moisture content. In order to avoid the need for irrigation during incubation and the subsequent passive movement of propagules from the seed to lower portions of the rhizosphere (Chao et al., 1986; Sivan \& Chet, 1989), the box with the tubes was placed in a transparent plastic bag to maintain constant soil moisture content. The boxes were incubated in a growth chamber at $25^{\circ} \mathrm{C}$ with $12 \mathrm{~h}$ of light per day. Soil columns with maize and cotton were incubated for 7 and $8 \mathrm{~d}$, respectively, at which time the roots of the most rapidly growing seedlings of each crop had reached the bottom of the soil columns.

After incubation, the tubes were removed from the box and their two halves were carefully separated. Roots were removed from the soil and measured. Six roots with a similar length were selected and cut into $2 \mathrm{~cm}$ segments, starting $2 \mathrm{~cm}$ above the seed. The scalpel used to cut roots was flamed between cuts to avoid transfer of inoculum from one segment to another. Comparable segments from replicate plants were transferred to $250 \mathrm{ml}$ Erlenymeyer flasks containing $40 \mathrm{ml}$ tap water and shaken vigorously for $1 \mathrm{~min}$ to remove the rhizosphere soil. The washed root segments and the hypocotyls were transferred to a second set of flasks containing $40 \mathrm{ml}$ tap water amended with $200 \mu \mathrm{l}$ Triton X100. Flasks containing the soil, as well as those containing the root segments, were then shaken on a rotary shaker for $1 \mathrm{~h}$ at 450 r.p.m. to suspend propagules of Trichoderma from the rhizosphere soil and rhizoplane, respectively. The suspensions from all flasks were transferred to $50 \mathrm{ml}$ tubes (Becton-Dickinson) and centrifuged at $4{ }^{\circ} \mathrm{C}$ for $10 \mathrm{~min}$ at $1600 \mathrm{~g}$ in order to concentrate the propagules. The supernatant was discarded and the pellets were resuspended in $1 \mathrm{ml}$ sterile tap water; serial dilutions were done and these plated on TSM.

The dry weight of root segments and the corresponding rhizosphere soil was determined after drying the samples at $70^{\circ} \mathrm{C}$ until no further change in weight was recorded $(20-24 \mathrm{~h})$. Population density of Trichoderma in rhizosphere soil or rhizoplane was expressed as c.f.u. per $g$ dry weight of rhizosphere soil or root segments, respectively, and presented as the $\log _{10}$ of that number. In order to determine the colonization level of the hypocotyl by $T$. harzianum strains the procedure described above for assessing the rhizoplane colonization was carried out on the first $2 \mathrm{~cm}$ hypocotyl segment.

In an additional experiment, aimed at comparing more closely the level of colonization of the root tip region among the tested strains, cotton and maize plants were grown as described above. In previous studies, particularly large differences were found in the level of colonization of this plant part when rhizosphere-competent and -noncompetent strains were compared (Ahmad \& Baker, 1987a). Plants with similar root lengths were selected and three $2 \mathrm{~cm}$ root segments were cut starting from the root tip. The segments, including the adhering soil, were shaken in $20 \mathrm{ml}$ tap water amended with $100 \mu \mathrm{l}$ Triton X-100 and the population density was determined as above and expressed as $\log _{10}$ [c.f.u. $(\mathrm{g} \text { dry wt })^{-1}$ ] of roots including the adhering rhizosphere soil. This experiment was comprised of four replicates of three plants each.

Confirmation of identity of rhizosphere-competent Trichoderma spp. Since all the experiments were performed in a natural field soil it was necessary to distinguish between rhizosphere soil and rhizoplane populations originating from the strains applied to seeds and those resulting from the natural soil population of Trichoderma. Therefore, in all experiments Trichoderma colonies were transferred from TSM to additional selective media and the frequency of $T$. harzianum strains similar to those applied to seeds was calculated. $T$. harzianum strain T95, which is resistant to benomyl, was transferred to PDA amended with $20 \mu \mathrm{g} \mathrm{ml}^{-1}$ (a.i.) of methyl 1-(butylcarbamoyl)-2-benzimidazolecarbamate (Benlate $50 \%$ a.i.; E. I. duPont Nemours Inc.). Native strains of Trichoderma usually will not tolerate concentrations greater than $3 \mu \mathrm{g} \mathrm{ml}^{-1}$. A second medium [CCNS; containing ( $\mathrm{g}$ per litre of PDA): chlorotetracycline, 0.1 ; cycloheximide, $0 \cdot 1$; nystatin, 0.02 ; and streptomycin sulphate, $0 \cdot 1]$ was similarly used to distinguish between T12, 1295-22 and contaminant Trichoderma spp. Most Trichoderma spp. grow poorly on this medium. On this medium strain T12 can readily be distinguished from 1295-22 on the basis of colony morphology and sporulation (Harman et al., 1989).

Reproducibility. All experiments were carried out twice.

\section{Results}

\section{Growth of maize and cotton in soil columns}

The average root elongation rate of maize was greater than that of cotton. In order to obtain sufficient numbers of plants of both crops with similar root lengths, cotton 


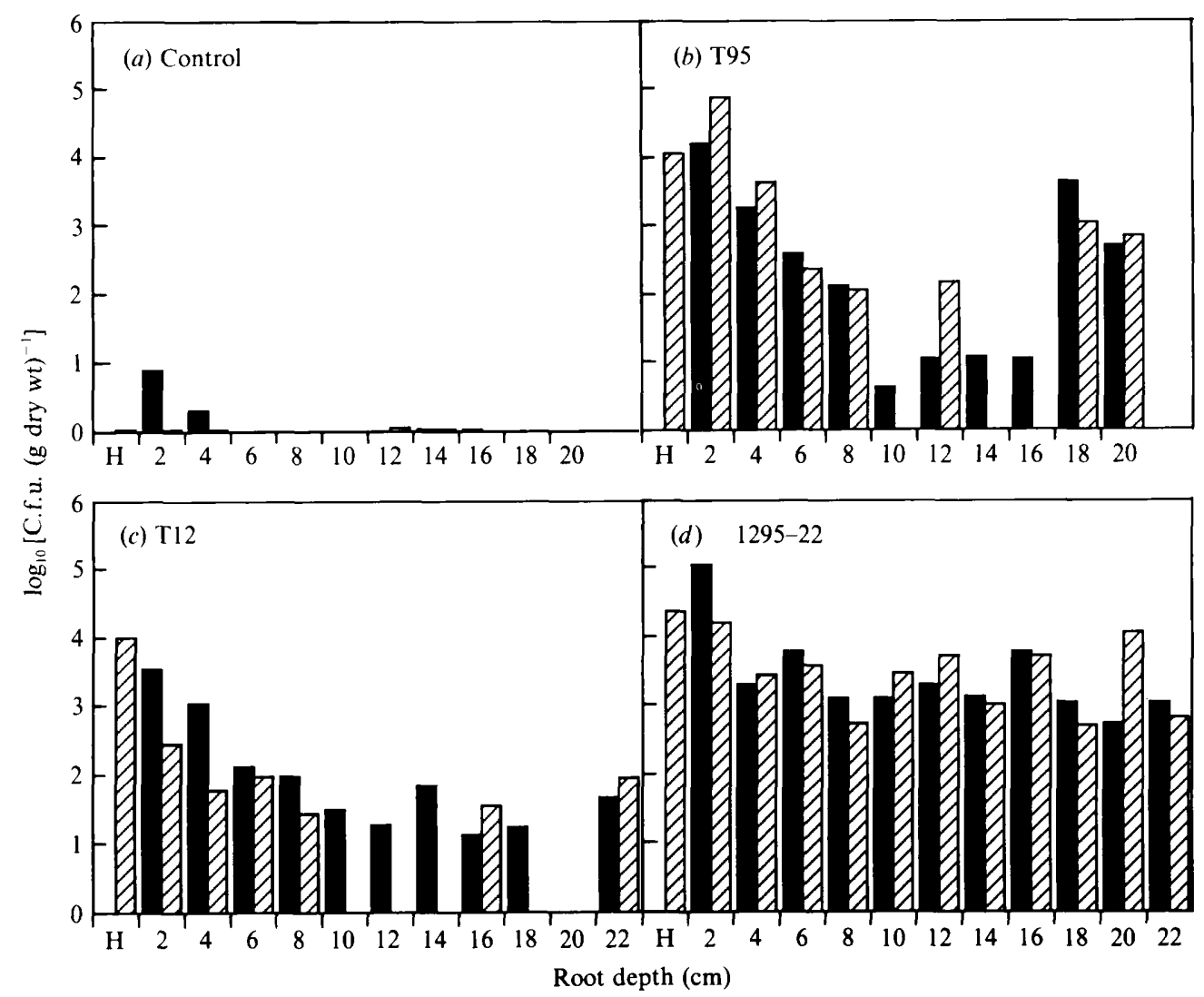

Fig. 1. Colonization of the rhizosphere soil, rhizoplane and hypocotyl $(\mathrm{H})$ of maize by $T$. harzianum. (a) No seed treatment; $(b-d)$ seed treatment with strain T95 $(b)$, strain T12 (c), and their protoplast fusion progeny 1295-22(d). Data are from a single representative experiment. $\mathbf{\square}$, Rhizosphere soil; $\mathbb{Z}$, rhizoplane.

Table 1. Effect of seed treatments with T. harzianum strains on root elongation of maize and cotton

Maize and cotton were grown in soil columns under constant soil moisture conditions for 7 and $8 \mathrm{~d}$, respectively. Values in each column followed by different letters are significantly different according to Waller and Duncan's test (GLM procedure, SAS Institute, Cary, NC, USA). Data are from a single representative experiment.

\begin{tabular}{lll}
\hline \hline & \multicolumn{2}{c}{ Root length $(\mathrm{cm})$} \\
\cline { 2 - 3 } Strain & Maize & Cotton \\
\hline Control & $16 \cdot 77^{c}$ & $13 \cdot 97^{c}$ \\
T12 & $21 \cdot 19^{a}$ & $16 \cdot 98^{b}$ \\
T95 & $18 \cdot 84^{b}$ & $17 \cdot 36^{b}$ \\
$1295-22$ & $22 \cdot 04^{a}$ & $22 \cdot 35^{a}$ \\
\hline \hline
\end{tabular}

plants were grown for $7 \mathrm{~d}$ and maize for $8 \mathrm{~d}$. All three $T$. harzianum strains increased the root elongation rate of both crops compared with that of the non-treated controls. Seed treatment with the protoplast fusion progeny 1295-22 resulted in the longest roots in both crops (Table 1).
Rhizosphere colonization pattern of $T$. harzianum strains

When non-treated seeds were sown in the soil columns, Trichoderma spp. could be isolated from the rhizosphere soil of only very few root segments (Figs $1 a, 2 a$ ). None of the isolated colonies could grow on PDA amended with benomyl ( $20 \mu \mathrm{g} \mathrm{ml}^{-1}$; a.i.); however, some of them grew on CCNS and were similar in morphology to the parental strain T12. Strain T12 was originally isolated from a similar soil (Hadar et al., 1984) so this result is not surprising. None of the colonies were similar to 1295-22.

In general, the maize rhizosphere was better colonized. than that of cotton (Figs 1 and 2, Table 2). Differences in patterns of colonization of roots by the three strains seemed to be most pronounced when specific regions, i.e. the upper $6 \mathrm{~cm}$, the lower $4 \mathrm{~cm}$, and the remaining middle portions, were considered (Figs 1 and 2). Therefore, values for these regions for each strain were combined across two experiments; the results are presented in Table 2. The greatest population densities of all strains tended to be on the upper portions of the roots, but differences in densities for specific strains along roots were not significant in 7 of the 12 root locationfungal strain combinations studied. Strain T95 was 

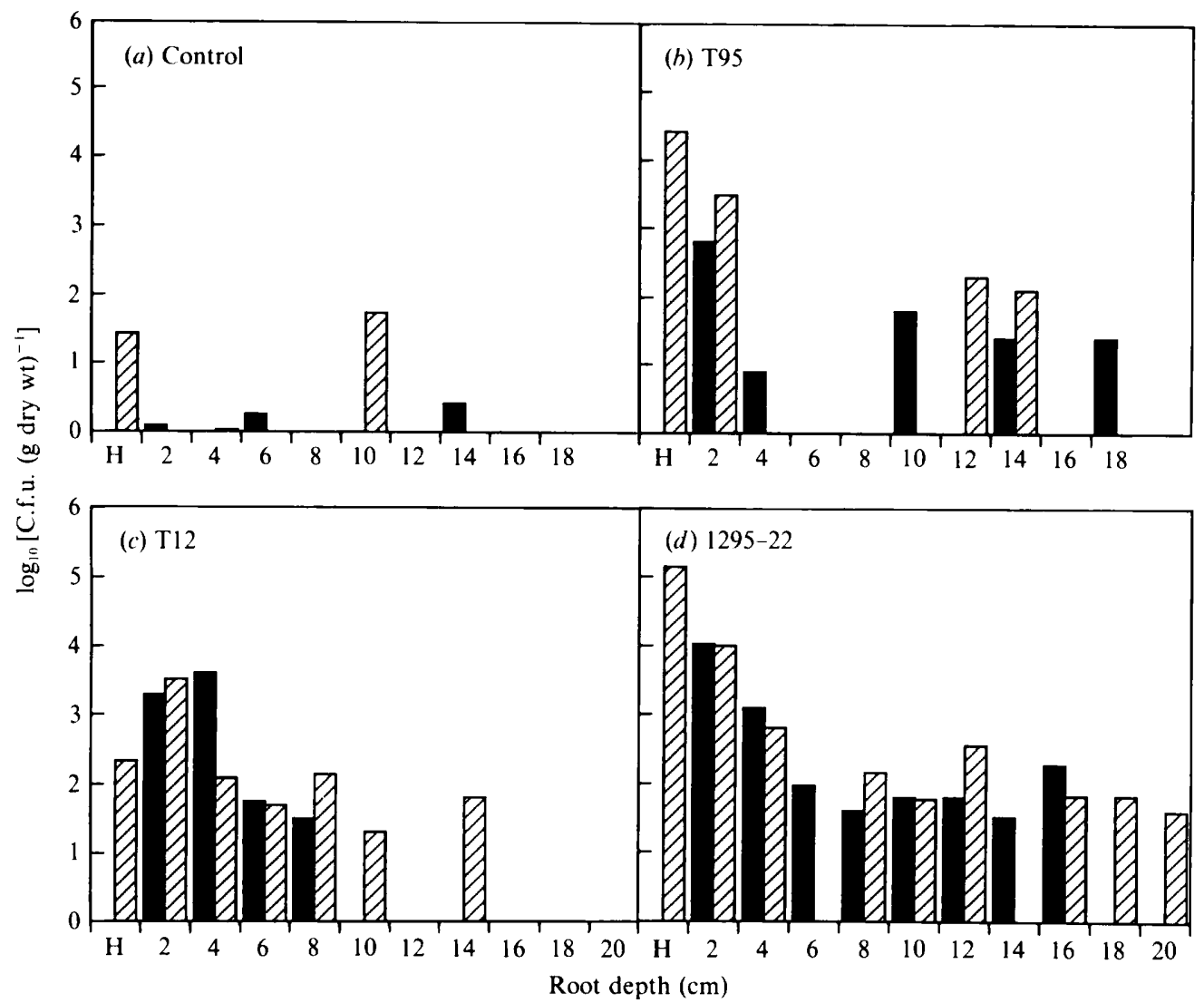

Fig. 2. Colonization of the rhizosphere soil, rhizoplane and hypocotyl $(\mathrm{H})$ of cotton by $T$. harzianum. (a) No seed treatment; $(b-d)$ seed treatment with strain T95 $(b)$, strain T12 $(c)$, and their protoplast fusion progeny 1295-22 $(d)$. Data are from a single representative

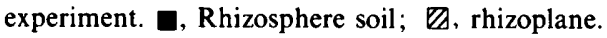

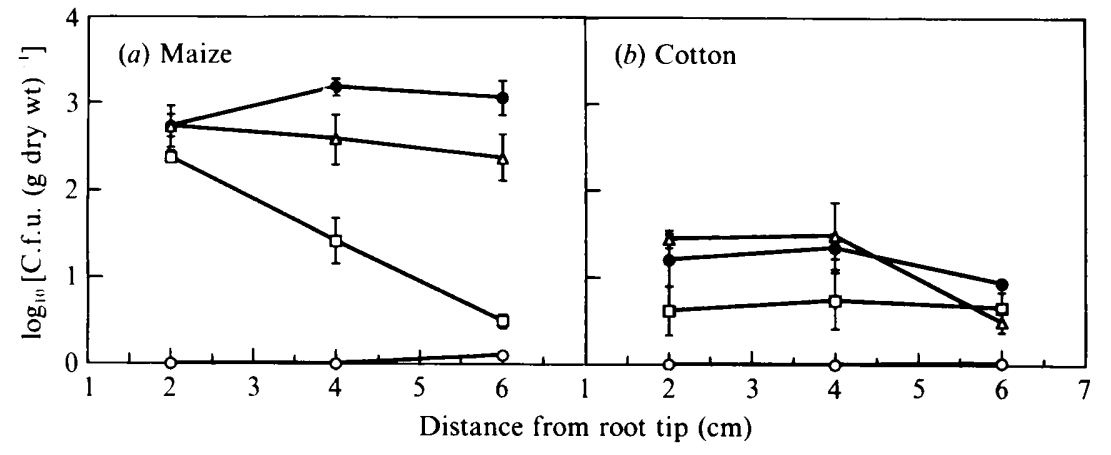

Fig. 3. Colonization of the root tip region of maize (a) and cotton (b) by T. harzianum strains T95, T12 and their protoplast fusion progeny 1295-22. The data represent the combined population density of rhizosphere soil and rhizoplane. Bars represent standard errors. Data are from a single representative experiment. $O$, Control (no seed treatment); $\triangle, T 95$; $\square, \mathrm{T} 12 ; 0,1295-22$. present at lower levels than strains T12 or 1295-22 on the upper root portions of cotton (Table 2, Fig. 2). Strains T95 and T12 were less effective than 1295-22 in colonizing the middle portions of roots. However, on the maize rhizosphere there were no significant differences between the three strains, even though the level of 129522 was about tenfold that of the parental strains (Table 2, Figs 1 and 2). No significant differences between strains were detected on the lower root regions of either crop
(Table 2). However, T95 was present at tenfold higher levels on the lower than on the middle rhizosphere of maize, and T12 was not detected on lower regions of cotton (Table 2, Fig. 2).

The hypocotyl of maize and cotton was colonized by all three strains. In both crops (except T12 on cotton) the population density level of this plant portion was similar to or higher than that obtained from the rhizoplane or from the rhizosphere soil (Figs 1 and 2). 
Table 2. Mean levels of the various strains of Trichoderma on the upper, middle, and lower rhizosphere and rhizoplane of maize and cotton roots

\begin{tabular}{|c|c|c|c|c|}
\hline \multirow{2}{*}{$\begin{array}{l}\text { Root } \\
\text { section }\end{array}$} & \multicolumn{3}{|c|}{$\log _{10}(\text { C.f.u. })^{*}$} & \multirow[b]{2}{*}{ MSD $\dagger$} \\
\hline & T95 & $1295-22$ & $\mathrm{~T} 12$ & \\
\hline \multicolumn{5}{|c|}{ Maize rhizosphere } \\
\hline Upper portion & $2 \cdot 5$ & $3 \cdot 9$ & $3 \cdot 3$ & NS \\
\hline Middle portion & $1 \cdot 2$ & $2 \cdot 9$ & 1.6 & $1 \cdot 08$ \\
\hline Lower portion & $2 \cdot 8$ & $3 \cdot 2$ & 1.8 & NS \\
\hline MSD + & NS & NS & $1 \cdot 52$ & \\
\hline \multicolumn{5}{|c|}{ Maize rhizoplane } \\
\hline Upper portion & $2 \cdot 8$ & $2 \cdot 4$ & $2 \cdot 6$ & NS \\
\hline Middle portion & $1 \cdot 2$ & $2 \cdot 9$ & 1.4 & NS \\
\hline Lower portion & 1.5 & $3 \cdot 1$ & $2 \cdot 4$ & NS \\
\hline MSD† & NS & NS & NS & \\
\hline \multicolumn{5}{|c|}{ Cotton rhizosphere } \\
\hline Upper portion & $1 \cdot 3$ & $2 \cdot 7$ & $2 \cdot 5$ & $1 \cdot 13$ \\
\hline Middle portion & 0.9 & $2 \cdot 0$ & $0 \cdot 6$ & $0 \cdot 80$ \\
\hline Lower portion & 0.6 & 0.7 & 0 & NS \\
\hline MSD ${ }^{+}$ & 0.45 & 1.66 & $1 \cdot 14$ & \\
\hline \multicolumn{5}{|c|}{ Cotton rhizoplane } \\
\hline Upper portion & 1.4 & $2 \cdot 6$ & $2 \cdot 4$ & $0 \cdot 74$ \\
\hline Middle portion & 0.8 & $2 \cdot 0$ & $1 \cdot 0$ & 1.07 \\
\hline Lower portion & $0 \cdot 4$ & $1 \cdot 3$ & 0 & NS \\
\hline MSD $\dagger$ & NS & NS & $0 \cdot 12$ & \\
\hline
\end{tabular}

* Units are per g dry weight of soil or root for rhizosphere or rhizoplane, respectively. In all cases, the upper portion of the roots were considered to be the first $6 \mathrm{~cm}$ below the hypocotyl, the lower portions were considered to be the lowest $4 \mathrm{~cm}$, and the remainder was considered to be the middle portion. Values presented are means across two separate experiments.

$\dagger$ Minimum significant difference as determined by Waller and Duncan's test (GLM procedure, SAS Institute, Cary, NC, USA).

\section{Colonization of the root tip region by $T$. harzianum strains}

Maize root tips were colonized similarly by all strains tested. However, the adjacent $4 \mathrm{~cm}$ of the root showed a decline in the population density levels of T12; this decline was not observed for the other two strains. The colonization level along various portions of the root by strain 1295-22 was similar to, but higher than, that of the parental strains (Fig. 3a). Conversely, no distinct difference in the level of root tip colonization of cotton could be observed among the tested strains (Fig. $3 b$ ).

\section{Discussion}

Protoplast fusion was effective in inducing rhizosphere competence in Trichoderma harzianum. This attribute has also been induced by mutation (Ahmad \& Baker, $1987 a$ ) and was recently demonstrated in a wild strain of T. harzianum (Sivan \& Chet, 1989).
Rhizosphere competence of beneficial microorganisms applied to seeds results in secondary deployment of these bioprotectants along the root (Harman, 1990). Thus, proliferation and colonization of the developing roots by $T$. harzianum may prevent root infection by root-rot and wilt pathogens (Sivan et al., 1987; Sivan \& Chet, 1989); in soil heavily infested with Pythium ultimum, roots of cucumber seedlings derived from seeds treated with strain 1295-22 were larger than those produced from seeds treated with T12 or T95 (Harman et al., 1989).

Previous reports indicated that rhizosphere-competent strains of $T$. harzianum, including strain T95, colonize the rhizosphere in a ' $\mathrm{C}$ ' shaped pattern, with higher establishment along the upper and lower portions of roots than in their central portions (Ahmad \& Baker, $1987 a, b$; Sivan \& Chet, 1989). In the present study, this pattern of colonization tended to occur with strain T95 on maize, although differences were not significant. On the other hand, population densities of the second parental strain, T12, which is not rhizosphere competent (Ahmad \& Baker, 1988; Chao et al., 1986), decreased with root depth on the rhizoplane of maize and the rhizosphere and rhizoplane of cotton, and was not detected on the lower root portions of cotton. The main improvement in rhizosphere colonization provided with 1295-22 was obtained along the middle portions of maize and cotton roots. A relatively high and uniform colonization pattern over the entire root length was obtained in both crops. Although population densities of all strains were, in general, lower on cotton roots than on those of maize, 1295-22 colonized more root segments than did the parental strains. Thus, its improved rhizosphere competence was not restricted to a single crop.

Substantial problems exist with methodology for quantitative and qualitative measurement of levels of root colonization by rhizosphere-competent fungi. Two general methods have been used: direct plating of root segments (Harman et al., 1989) and dilution plating of washings from root segments, as used in this work and elsewhere (e.g. Ahmad \& Baker, 1987a; Sivan \& Chet, 1989). Neither method is totally satisfactory. Direct plating of roots measures only the presence or absence of propagules, and provides no information on the quantity of fungus. Data obtained by dilution plating of root washings may be skewed if conidia are present, since a single conidiophore could provide many more propagules than a larger quantity of hyphal biomass. However, dilution plating may accurately portray quantities of rhizosphere-competent $T$. harzianum on roots. Ahmad \& Baker (1987a) found that the total length of hyphae of the rhizoplane of roots roughly paralleled population densities as determined by dilution plating. Kleifeld \& 
Chet (1990), in microscopic observations, found hyphae, but no conidia, on roots following a soil treatment with a Trichoderma strain. In earlier studies with the same three strains used in this study, strain 1295-22 was found to be a colonist of a greater percentage of root segments of field-grown mature garden peas than either T95 or T12. Further, in experiments with cucumber seedlings in the presence of $\boldsymbol{P}$. ultimum, seed treatment with 1295-22 provided greater root volumes than treatment with the other two strains, presumably due to greater protection of root systems against the pathogen (Harman et al., 1989). These results are consistent with those in the present study indicating that strain 1295-22 is more strongly rhizosphere competent than either parental strain.

In order to proliferate along the roots, rhizospherecompetent strains must overcome competition imposed by the indigenous rhizosphere microflora (Chao et al., 1986). The mechanism(s) of rhizosphere competence are still unclear. However, strain $1295-22$ grows more rapidly than either parental strain at $25^{\circ} \mathrm{C}$ or $11^{\circ} \mathrm{C}$. Further, Ahmad \& Baker (1987b) demonstrated a direct correlation between the cellulolytic activity of benomyl-tolerant mutants of $T$. harzianum (including T95) and their rhizosphere competence. These mutants were able to utilize different qualitative forms of cellulose and xylan (Ahmad \& Baker, 1988) which are present on the rhizoplane of roots (Foster et al., 1983). Another mechanism which may contribute to the successful colonization of the rhizosphere by certain strains could involve utilization of energy and nitrogen sources present in root exudates. Most of the nutrients are exuded from root portions close to the root tip and therefore strains that are able to utilize these nutrients more efficiently than the indigenous rhizosphere microflora may have an ecological advantage. When compared with the parental strains, strain 1295-22 was better than T95 or T12 in its ability to colonize the regions just above the root tip of maize but not of cotton (Fig. 3). However, since the main improvement in the rhizosphere colonization obtained with 1295-22 on both crops was on the middle portion of the root, the contribution of root exudates to the improved rhizosphere competence of 1295-22 remains unclear.

The association of rhizosphere competence with biological control and increase in plant growth response has not yet been determined. In the present study, plants grown from seeds treated with strain 1295-22 produced longer roots than those grown from seeds treated with the parental strains. Strain 1295-22 also exhibited a significant improvement in the biological control of $P$. ultimum (Harman et al., 1989). However, more studies are needed in order to provide a better understanding of the mechanisms conferring rhizosphere competence and its possible relation to biological control and increased plant growth responses. Investigations on the genetic basis of improved rhizosphere competence of strain 1295-22 are under way.

This research was supported in part by grants from the Cornell Biotechnology Program, which is sponsored by the New York Science and Technology Program and a consortium of industries; from the USIsrael Binational Agricultural Research and Development Fund (BARD) US-1224-86, and from the Eastman Kodak Co.

We thank M. C. Matteson and P. A. Nielsen for technical assistance.

\section{References}

Ahmad, J. S. \& Baker, R. (1987a). Rhizosphere competence of Trichoderma harzianum. Phytopathology 77, 182-189.

AHMAD, J. S. \& BAKER, R. (1987b). Competitive saprophytic ability and cellulolytic activity of rhizosphere competent mutants of Trichoderma harzianum. Phytopathology 77, 358-362.

AHMAD, J. S. \& BAKER, R. (1988). Rhizosphere competence of benomyl-tolerant mutants of Trichoderma spp. Canadian Journal of Microbiology 34, 694-698.

BurR, T. J., SChroth, M. N. \& Suslow, T. V. (1978). Increased potato yield by treatment of seedpieces with specific strains of Pseudomonas fluorescens and P. putida. Phytopathology 68, 1377-1383.

Chao, W. L., Nelson, E. B., Harman, G. E. \& Hoch, H. C. (1986). Colonization of the rhizosphere by biological control agents applied to seeds. Phytopathology 76, 60-65.

CHET, I. (1987). Trichoderma - application, mode of action, and potential as a biocontrol agent of soilborne plant pathogens. In Innovative Approaches to Plant Disease Control, pp. 137-160. Edited by I. Chet. New York: John Wiley.

Elliott Juhnke, M., Mathre, D. E. \& Sands, D. C. (1987). Identification and colonization of rhizosphere-competent bacteria of wheat. Applied and Entironmental Microhiology 53, 2793-2799.

Foster, R. C., Rovira, A. D. \& COCK, T. W. (1983). Ultrastructure of the Root-Soil Interface. St Paul, MN, USA : American Phytopathological Society.

Hadar, Y., HaRMan, G. E. \& TAYloR, A. G. (1984). Evaluation of Trichoderma harzianum and $T$. koningii from New York soils for biological control of seed rot caused by Phythium spp. Phytopathology 74, $106-110$.

Harman, G. E. (1990). Deployment tactics for biocontrol agents in plant pathology. In New Directions in Biological Controls (UCLA Symposia on Molecular and Cellular Biology, vol. 112), pp. 779-792. Edited by R. Baker \& P. Dunn. New York: Alan R. Liss.

HARMAN, G. E., CHET, I. \& BAKER, R. (1981). Factors affecting Trichoderma hamatum applied to seeds as a biocontrol agent. Phytopathology 71, 569572.

Harman, G. E., Taylor, A. G. \& Stasz, T. E. (1989). Combining effective strains of Trichoderma harzianum and solid matrix priming to improve biological seed treatments. Plant Disease 73, 631-637.

Hubbard, J. P., Harman, G. F. \& Hadar, Y. (1983). Effect of soilborne Pseudomonas spp. on the biological control agent, Trichoderma hamatum, on pea seeds. Phytopathology 73, 655-659.

K LEIFELD, O. \& CHET, J. (1990). Trichoderma plant interaction and its effect on increased growth response. Plant and Soil (in the Press).

PAPAVIZAS, G. C. (1982). Survival of Trichoderma harzianum in soil and in pea and bean rhizospheres. Phytopathology 72, 121-125.

Papavizas, G. C. (1985). Trichoderma and Gliocladium: biology, ecology and the potential for biocontrol. Annual Review of Phytopathology 23, 23-54.

SCher, F. M., Ziegle, J. S. \& Kloepper, J. W. (1984). A method for assessing the root colonization capacity of bacteria on maize. Canadian Journal of Microbiology 30, 151-157. 
Schmidt, E. L. (1979). Initiation of plant-microbe interactions. Annual Review of Microbiology 33, 355-376.

Sivan, A. \& ChET, I. (1989). The possible role of competition between Trichoderma harzianum and Fusarium oxysporum in rhizosphere colonization. Phytopathology 79, 198-203.

SivaN, A. \& HARMAN, G. E. (1989). Increase in rhizosphere competence of Trichoderma harzianum following protoplast fusion. Phytopathology 79, 1159.

Sivan, A. \& HaRMan, G. E. (1989). Improved rhizosphere competence of Trichoderma harzianum by protoplast fusion. Plant and Soil (in the press).
Sivan, A., Ucko, O. \& CHET, I. (1987). Biological control of Fusarium crown rot of tomato by Trichoderma harzianum under field conditions. Plant Disease 71, 587-592.

Stasz, T. E., Harman, G. E. \& Weeden, N. F. (1988). Protoplast preparation and fusion in two biocontrol strains of Trichoderma harzianum Mycologia 80, 141-150. 